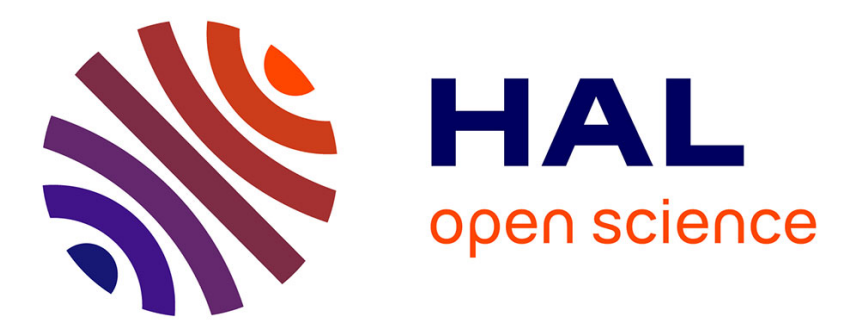

\title{
Transient performance of a magnetically geared induction machine
}

\author{
Badr-El-Boudour Bidouche, Thierry Lubin, Smail Mezani
}

\section{To cite this version:}

Badr-El-Boudour Bidouche, Thierry Lubin, Smail Mezani. Transient performance of a magnetically geared induction machine. COMPEL: The International Journal for Computation and Mathematics in Electrical and Electronic Engineering, 2020, 39 (5), pp.1113-1130. 10.1108/COMPEL-12-2019-0485 . hal-02900892

\section{HAL Id: hal-02900892 \\ https://hal.science/hal-02900892}

Submitted on 16 Jul 2020

HAL is a multi-disciplinary open access archive for the deposit and dissemination of scientific research documents, whether they are published or not. The documents may come from teaching and research institutions in France or abroad, or from public or private research centers.
L'archive ouverte pluridisciplinaire HAL, est destinée au dépôt et à la diffusion de documents scientifiques de niveau recherche, publiés ou non, émanant des établissements d'enseignement et de recherche français ou étrangers, des laboratoires publics ou privés. 


\title{
Transient Performance of a Magnetically Geared Induction Machine
}

\author{
Badr-El-Boudour Bidouche, Thierry Lubin, Smaïl Mezani \\ Groupe de Recherche en Energie Electrique de Nancy (GREEN), \\ Université de Lorraine, 54506 Vandoeuvre-lès-Nancy,France \\ thierry.lubin@univ-lorraine.fr
}

\begin{abstract}
Purpose - The purpose of this paper is to investigate the transient performance of an induction machine coupled with a magnetic gear for industrial applications with low speed and high torque requirements. This new solution increases mechanical reliability and does not require maintenance and lubrication. The main objective is to study the direct-on-line starting ability of the electrical machine and its stability regarding a sudden variation of the load torque.
\end{abstract}

Design/Methodology/Approach - A non-linear analytical model for the induction machine and the magnetic gear is first developed. The model is then linearized around an operating point to obtain the transfer function between the load angle and the electromagnetic torque from which an analytical expression for the mechanical resonant frequency is obtained.

Finding - It is shown that the direct on-line starting is possible if the moment of inertia of the load is not greater than a maximum value. Moreover, it is demonstrated that this new system present inherent overload protection.

Originality/Value - A new high-performance direct-on-line starting electrical machine is proposed to achieve high torque at low speed without mechanical gear to improve reliability and reduce maintenance.

Keywords - Induction motor, magnetic gear, transient model, stability

\section{Introduction}

A new concept of a Magnetically Geared Induction Motor (MaGIM) was introduced by (Mezani, 2015) in order to replace the conventional system that combines an induction motor IM to a mechanical gear for applications with low speed and high torque requirements. The main objective is to improve performance and reliability. A design procedure for a MaGIM rated at 1 $\mathrm{kW}-45 \mathrm{rpm}$ and intended for a constant speed operation on the grid (400V/50Hz) has been developed in (Bidouche, 2018). Both electromagnetic and thermal analyses have been carried out using analytical computation tools. This design was carried out to optimize the steady state operation.

The present paper addresses transient analyses of MaGIM. Indeed, dynamic model is one of the key steps to validate the design process of an electrical actuator (Adkins, 1975). Because the MaGIM integrates a magnetic gear whose torsional stiffness is much lower than mechanical gears, oscillations of speed and torque usually appear during transient variations of load. A passive reduction of the oscillations in magnetic gears can be obtained using damper windings as in synchronous generators. The authors in (Franck, 2011) showed the benefit of using dampers in reducing oscillations and settling time but additional losses due to space harmonics may be important. In magnetically geared PM machines (Montague, 2013), (Bouheraoua, 2015), linear and non-linear control strategies are proposed to ensure better stability and rapid recovery from slipping during transient operation of magnetically-geared drive-trains. 
The computation of the transient behavior of magnetically geared machines can be done by finite element analyses (Ho, 2010, Franck, 2011). Obviously, this leads to precise predictions of the electromechanical quantities taking into account magnetic saturation and circuit coupling. Nevertheless, FE methods solve time-dependent PDEs which requires long computation time not compatible with real time control requirements.

The preferred method for transient analyses of magnetic gears employs circuit models coupled to mechanical equations to predict the transient state by solving ODEs (Desvaux, 2016). This technique is used in this paper in connection with the dq model of an induction motor to study the dynamic behavior of a MaGIM that operates on the grid. One question to be answered is: can this machine start on the grid without problem of stability for the magnetic gear?

\section{Operating principle of the MaGIM}

The MaGIM is shown in Fig. 1. It consists of a magnetic gear (Rasmussen 2005, Hafla 2007, Lubin 2010) coupled to a reverse type induction motor with $p$ pole pairs. The magnetic gear represents the external part of the MaGIM while the IM represents the internal part (wound rotor machine). The high-speed (HS) rotor is the common part of the IM and the gear. The conventional magnetic gear involves two rotors and a fixed armature (Atallah 2001, Da Costa Neves 2016).

The MaGIM is supplied by the grid and can be used for low speed application requiring high starting torque. The electromagnetic torque from the IM moves the high-speed rotor. Then the magnetic field created in the air-gap by the $p_{i}$ polepairs permanent magnets (PM) of inner HS rotor is modulated by the $P_{s}$ ferromagnetic pole pieces. The external armature being held stationary, the obtained field interacts with the magnetic field generated in the airgap by the $p_{o}$ PM pole-pairs of this armature in order to transmit the torque to the low-speed (LS) rotor (Liu 2009, Filippini 2017). The combination $p_{o}=P_{s}-p_{i}$ results in the highest torque transmission capability of the gear (Atallah, 2001). The resulting gear ratio $\mathrm{G}_{\mathrm{r}}$ is given by:

$$
G_{r}=\frac{P_{s}}{p_{i}}
$$

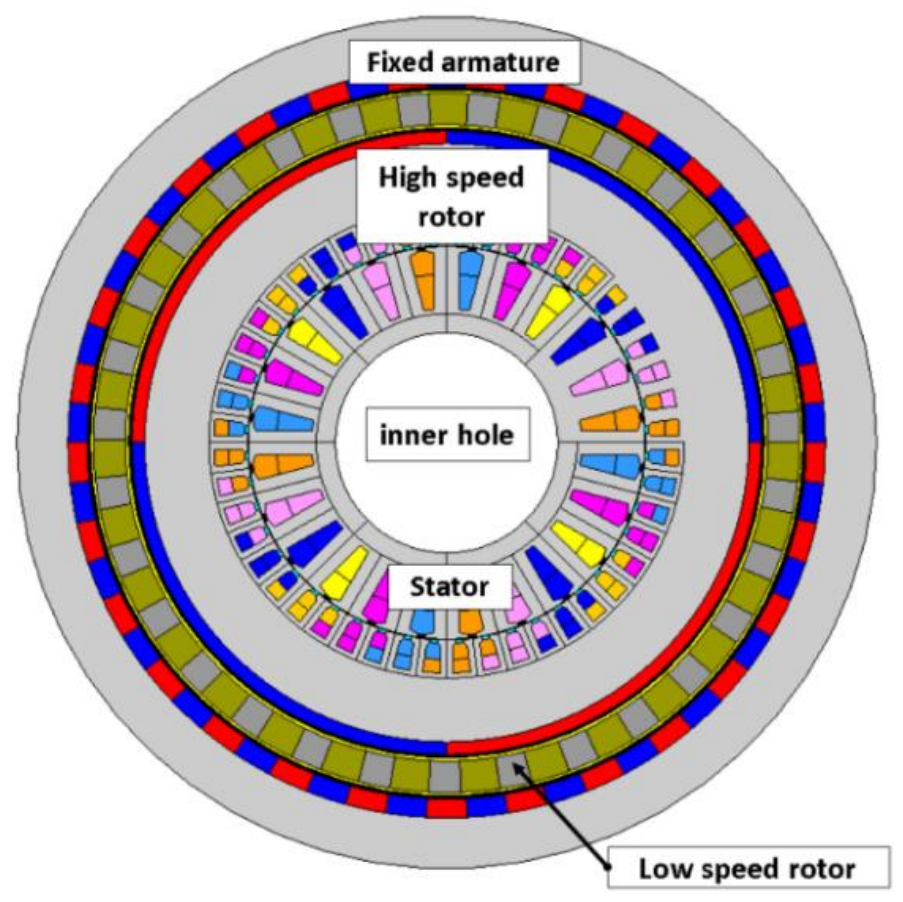

Fig. 1. 2D view of the MaGIM with $p_{i}=2, P_{s}=31$ and $p_{o}=29$. 
To achieve the electromagnetic design of the MaGIM, analytical models for preliminary computations and finite-element simulations for more precise results were used (Bidouche, 2018). With the active dimensions obtained by the electromagnetic design, the gear exhibits a pull-out torque of $350 \mathrm{Nm}$. Table 1 gives the values of the main parameters of the MaGIM.

\section{Transient Model of the MaGIM}

A classical transient $d-q$ model for the IM is used (Adkins, 1975). This model is based on the theory of magnetically coupled electrical circuits. This model, linked to the stator $\left(\omega_{s}=0\right)$, is obtained by using Park's transformation. As shown in (2), this model is written by highlighting the measurable and easily accessed electrical parameters of the induction machine, such as the rotor time constant $\tau_{r}$ and the total leakage coefficient $\sigma$. In (2), $I_{d s}, I_{q s}$ are the stator current in the $d$ - $q$ reference frame, and $\varphi_{d r}$ and $\varphi_{q r}$ are the rotor flux. The pulsation $\Omega_{h s}$ is the IM rotor speed (high-speed) and $p$ is the number of pole-pairs of the IM. The electromagnetic torque can be defined as a function of these variables (3).

$$
\left\{\begin{array}{c}
\frac{d I_{d s}}{d t}=-\frac{1}{\sigma L_{s}}\left[\left(R_{s}+\frac{M^{2}}{L_{r} \tau_{r}}\right) I_{d s}-\frac{M}{L_{r} \tau_{r}} \varphi_{d r}-\frac{M}{L_{r}} p \Omega_{h s} \varphi_{q r}+V_{d s}\right] \\
\frac{d I_{q s}}{d t}=-\frac{1}{\sigma L_{s}}\left[\left(R_{s}+\frac{M^{2}}{L_{r} \tau_{r}}\right) I_{q s}-\frac{M}{L_{r}} p \Omega_{h s} \varphi_{d r}-\frac{M}{L_{r} \tau_{r}} \varphi_{q r}+V_{q s}\right] \\
\frac{d \varphi_{d r}}{d t}=\frac{M}{\tau_{r}} I_{d s}+\frac{1}{\tau_{r}} \varphi_{d r}-p \Omega_{h s} \varphi_{q r} \\
\frac{d \varphi_{q r}}{d t}=\frac{M}{\tau_{r}} I_{d s}-p \Omega_{h s} \varphi_{d r}+\frac{1}{\tau_{r}} \varphi_{q r} \\
\Gamma_{e m}=p \frac{M}{L_{r}}\left(\varphi_{d r} . I_{q s}-\varphi_{q r} . I_{d s}\right)
\end{array}\right.
$$

The main parameters for the IM and for the magnetic gear are given in Table 1 (Bidouche, 2018).

TABLE 1. PARAMETERS OF THE MAGIM

\begin{tabular}{c|c}
\hline Magnetic gear parameter & Value \\
\hline Inner rotor pole-pairs $p_{i}$ & 2 \\
\hline Stationary armature poles-pairs $p_{o}$ & 29 \\
\hline Number of ferromagnetic pole-pieces $P_{s}$ & 31 \\
\hline Gear ratio $G_{r}$ & 15.5 \\
\hline Pull-out torque $\boldsymbol{\Gamma}_{\max }$ & $350 \mathrm{Nm}$ \\
\hline IM electrical parameter & Value \\
\hline Stator inductance $L_{s}$ & $0.3 \mathrm{H}$ \\
\hline Rotor inductance $L_{r}$ & $0.08 \mathrm{H}$ \\
\hline Mutual inductance $M$ & $0.15 \mathrm{H}$ \\
\hline Stator resistance $R_{s}$ & $6.6 \Omega$ \\
\hline Rotor resistance $R_{r}$ & $2.2 \Omega$ \\
\hline Rotor time constant $\tau_{r}$ & $36 \mathrm{~ms}$ \\
\hline Total leakage coefficient $\sigma$ & 0.062 \\
\hline Number of pole-pairs $p$ & 4 \\
\hline
\end{tabular}

The gear ratio being relatively high, the IM transmits a low torque value on the HS rotor. Hence, it was possible to achieve a MaGIM design (Bidouche 2018) with a relative low value for the flux density in the teeth (around 1.3T) and the air-gap (around $0,6 \mathrm{~T}$ ) of the IM which works practically under linear condition in steady-state. Therefore, a linear d-q model as the one used in this paper with the parameters given in Table 1 is sufficient to predict the transient performance of the MaGIM. Moreover, the electromagnetic torque pulsations at $50 \mathrm{~Hz}$ are largely filtered by the mechanical system as shown in Fig. 5. As a result, the 
maximum value reached by the electromagnetic torque during the starting will have a little impact on the stability, even though magnetic saturation is taken into account in the modeling.

To take into account the magnetic saturation on the transient performances, a saturation factor could be added in the d-q model (Brown 1983). This saturation factor can be obtained by the no load test or computed by finite element simulations. As known, this saturation factor depends on the electrical currents in the machine (stator and rotor) and has an impact on the stator and rotor flux-linkages (so on the electromagnetic torque as well) during the transient.

The block diagram of the MaGIM is given in Fig. 2 where $J_{h}$ and $J_{l}$ are the moment of inertia of the HS and LS rotors respectively, $F_{h}$ and $F_{l}$ are the friction coefficients, and $\Gamma_{e m}, \Gamma_{h}, \Gamma_{l}$, and $\Gamma_{c h}$ represent the electromagnetic, the HS, the LS, and the load torque, respectively.

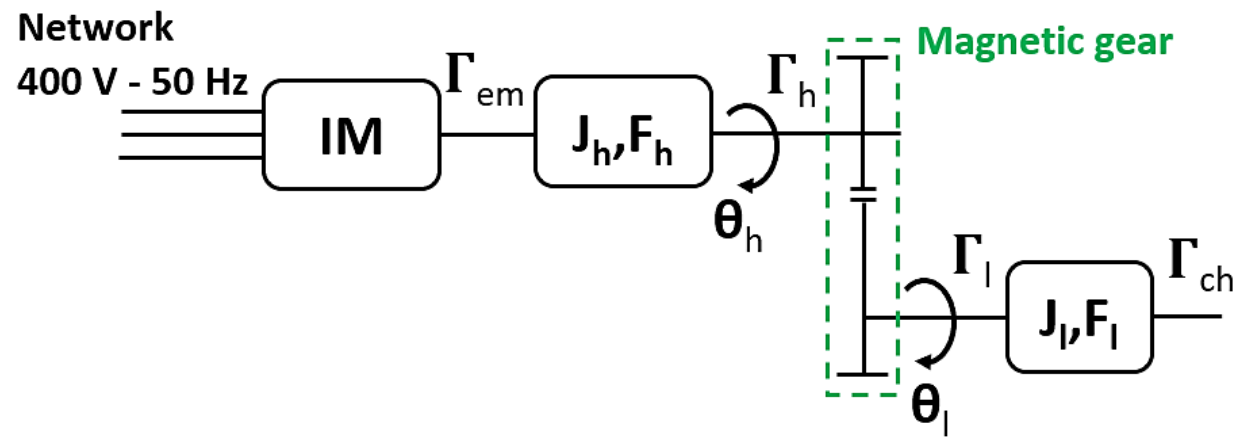

Fig. 2. Block diagram of the MaGIM

The mechanical model of the magnetic gear is obtained from the second Newton's law. As shown in Fig. 3, we consider a sinusoidal variation with respect to the load angle $\Phi$ for $\Gamma_{h}$ and $\Gamma_{l}$ (Atallah 2001, Mezani 2015). For a magnetic gear, the torque ripples depend on the pole-pairs combination between the two rotors. It is shown in (Atallah 2001, Zhu 2000) that the torque ripples decrease with the cogging torque factor $C_{f}$ which depends on $p_{o}$ and $P_{s}$. For the studied magnetic gear, we have $p_{o}=29$ and $P_{s}=31$, which results in the minimal value of $C_{f}=1$. Therefore, the torque is practically ripple-free so we can assume a sinusoidal variation of $\Gamma_{h}$ and $\Gamma_{l}$ with the load angle $\Phi$.

The dynamic equations are written for each rotor as reported in (4). The load angle $\Phi$ is defined in (5).

$$
\left\{\begin{array}{c}
\frac{d \Omega_{h s}}{d t}=\frac{1}{J_{h}} \Gamma_{e m}-\frac{F_{h}}{J_{h}} \cdot \Omega_{h s}-\frac{\Gamma_{\max }}{J_{h} \cdot G_{r}} \cdot \sin (\phi) \\
\frac{d \Omega_{l s}}{d t}=\frac{\Gamma_{\max }}{J_{l}} \cdot \sin (\phi)-\frac{F_{l}}{J_{l}} \cdot \Omega_{l s}-\frac{\Gamma_{c h}}{J_{l}} \\
\phi=p_{i} \cdot \theta_{h}-P_{s} \cdot \theta_{l}
\end{array}\right.
$$

with $\Omega_{h s}=d \theta_{h} / d t$ and $\Omega_{I s}=d \theta_{l} / d t$.

\section{Linearized magneto-mechanical model of the magnetic gear}

Considering a sinusoidal variation for the transmitted torque as shown in Fig. 3, the HS and LS torque $\Gamma_{h}$ and $\Gamma_{l,}$ depend on the magnetic gear properties such as the maximal torque $\Gamma_{\max }$, the load angle $\Phi$ defined in (5) and the gear ratio $\mathrm{G}_{\mathrm{r}}$. 
As shown in (4), the mechanical transient model of the MaGIM is non-linear due to the sinusoidal term. In order to obtain a linear model, a first order Taylor expansion of the sine function is considered around an operating point corresponding to $\Phi=$ $\Phi_{0}$. This gives us the natural frequency expression of the shaft line shown in Fig. 2. As shown in Fig. 3, the operating point is defined for a load torque value $\Gamma_{l 0}$ that corresponds to $\Phi_{0}$, where $\Phi_{0}<\frac{\pi}{2}$ and $\Gamma_{l 0}<\Gamma_{\max }$.

The use of Laplace transform allows writing the linear equations of the magnetic gear in matrix form (6). This system of equations reveals an important parameter called the torsional stiffness coefficient $K(\mathrm{Nm} / \mathrm{rad})$ given by (7). The torsional stiffness $K$ depends on the parameters $\Gamma_{\max }$ and $P_{s}$ of the magnetic gear. Its value for the studied magnetic gear is around $10 \mathrm{kNm} / \mathrm{rad}$, which is 50 times smaller than the torsional stiffness coefficient of a classical mechanical gear whose typical value is greater than $50 \mathrm{kNm} / \mathrm{rad}$. This low value for the torsional stiffness will be the source of large oscillations in the speed response during the transient, as shown later in the paper.

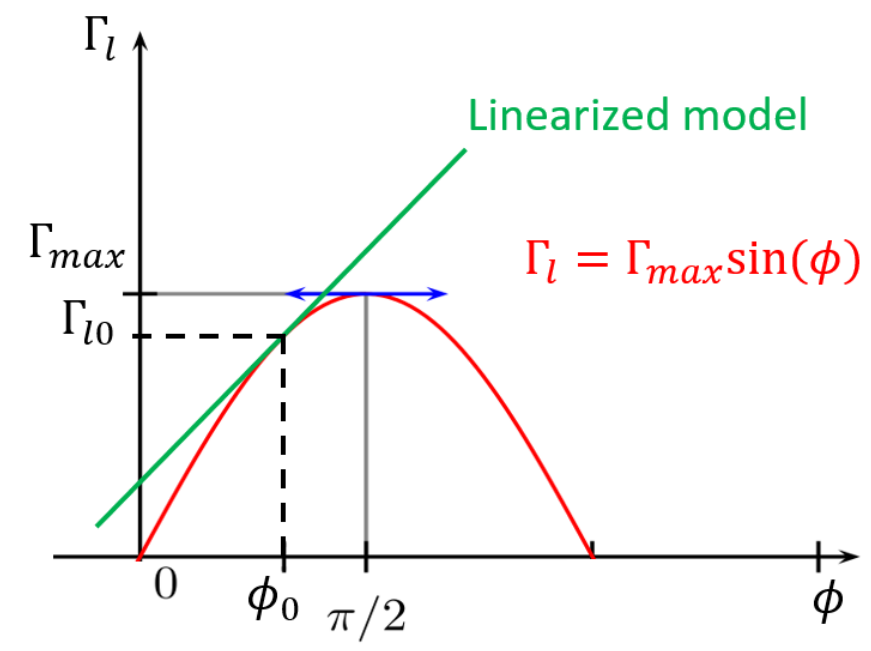

Fig. 3. Low speed torque as a function of the load angle

$$
\begin{gathered}
{\left[\begin{array}{cc}
J_{h} s^{2}+F_{h} s+\frac{K}{G_{r}{ }^{2}} & -\frac{K}{G_{r}} \\
-\frac{K}{G_{r}} & J_{l} s^{2}+F_{l} s+K
\end{array}\right]\left[\begin{array}{c}
\theta_{h}(s) \\
\theta_{l}(s)
\end{array}\right]=\left[\begin{array}{c}
\Gamma_{e m}(s) \\
-\Gamma_{c h}(s)
\end{array}\right]} \\
K=P_{s} \Gamma_{\text {max }} \cos \phi_{0}
\end{gathered}
$$

To study the impact of the IM electromagnetic torque $\Gamma_{e m}$ on the load angle of the magnetic gear, we obtain from (5) and (6) the transfer function of the MaGIM:

$$
F_{t}(s)=\frac{\phi(s)}{\Gamma_{e m}(s)}=A \frac{1+\tau_{1} s}{\left(1+\tau_{2} s\right)\left(1+\frac{2 m}{\omega_{0}} s+\frac{1}{\omega_{0}^{2}} s^{2}\right)}
$$

This corresponds to a third-order transfer function. From (6), (7) and (8), it is possible to identify the parameters of the transfer function: the steady state gain $A$, the time constants $\tau_{1}$ and $\tau_{2}$, the undamped resonant frequency $\omega_{0}$ and the damping factor $m$. It is important to note that the parameters of the transfer function (8) depend on the operating point characterized by $\Phi_{0}$. These parameters are expressed in the following equations 


$$
\begin{gathered}
A=\frac{F_{l} p_{i}}{K\left(F_{h}+\frac{F_{l}}{G_{r}^{2}}\right)} \quad \tau_{1}=\frac{J_{l}}{F_{l}} \quad \tau_{2}=\frac{J_{h}+\frac{J_{l}}{G_{r}^{2}}}{F_{h}+\frac{F_{l}}{G_{r}^{2}}} \\
\omega_{0}=\sqrt{K\left(\frac{1}{J_{l}}+\frac{1}{G_{r}^{2} J_{h}}\right)} \\
m=\frac{F_{h} F_{l}}{2 K\left(F_{h}+\frac{F_{l}}{G_{r}^{2}}\right)} \omega_{0}
\end{gathered}
$$

Fig.4 shows the Bode diagram corresponding to the third-order transfer function (8) with the parameters given in Table 1 and Table 2 and by considering $\Phi_{0}=0$ (no-load condition). The Bode's diagram gives us a simplified graphical representation of (8) in order to study the MaGIM behavior in the frequency domain.

We can observe in Fig. 4 that the gain amplitude goes to a maximum value of around $-5 \mathrm{~dB}$ for a resonant frequency of 47 $\mathrm{rad} / \mathrm{s}$. The gain amplification at this frequency highlights the classical resonance phenomenon. This phenomenon is amplified by the low value of the damping coefficient (11) which is equal to $m=0.043$ for the studied line shaft. It is important to note that if an electromagnetic torque of the IM is characterized by a pulsation close to this resonant frequency, the disturbances will be amplified and the risk of overload becomes significant. We can define a similar Bode diagram with respect to the load torque (with the same resonant frequency) with the same conclusion.

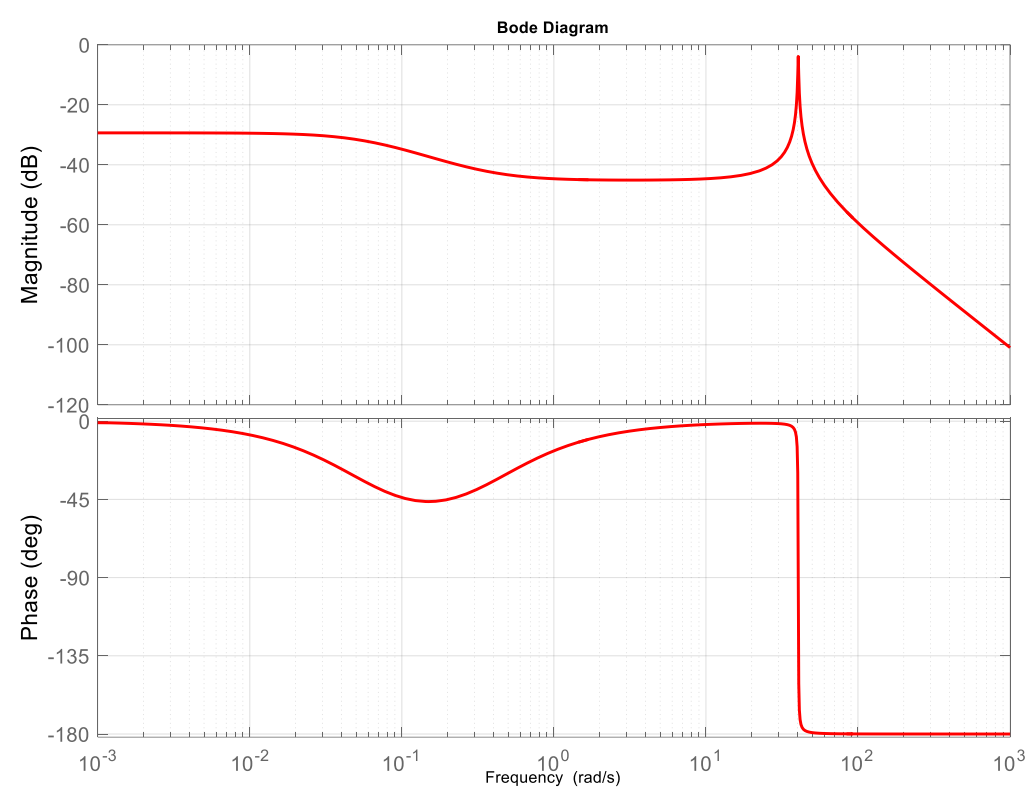

Fig. 4. Bode diagram of the transfer function $F_{t}(s)$

\section{Results and discussions}

In order to validate the established analytical models, simulation studies that uses the non-linear models of the induction machine and the magnetic gear (2)-(5) are conducted (MaGIM parameters are given in Tables 1 and 2).

In this section, the dynamic behavior of the MaGIM is first evaluated for a direct on-line start at rated voltage and frequency $(400 \mathrm{~V} ; 50 \mathrm{~Hz})$ and under no-load condition. The main objective is to verify if the MaGIM can start without dropping out. Then we study the speed responses to a load torque step of $100 \mathrm{Nm}$ and for overload condition. In order to show the impact of the resonant frequency on the load angle, a load torque combining an average value and a sinusoidal disturbance with different 
frequency values will be applied to the MaGIM. The main objective is to show the impact of the resonant frequency on the load angle. Finally, we will show the influence of the load inertia $J_{l}$ on the transient responses.

\subsection{Direct on-line start}

A direct on-line start under no-load condition is firstly studied. The mechanical parameters of the MaGIM are given in table 2. It is important to note that $J_{l}$ includes the load inertia. Fig. 5 shows the speed variations for the LS and HS rotors during the start-up. Fig. 6 shows the torque on the LS and HS rotors, and the electromagnetic torque of the induction machine. Fig. 7 gives the load angle variation during the starting.

TABle 2 Mechanical parameters of the MaGIM

\begin{tabular}{l|c}
\hline \multicolumn{1}{c|}{ Mechanical parameter } & Value \\
\hline HS rotor inertia $J_{h}$ & $0.2 \mathrm{~kg} \cdot \mathrm{m}^{2}$ \\
\hline LS rotor and load inertia $J_{l}$ & $4.6 \mathrm{~kg} \cdot \mathrm{m}^{2}$ \\
\hline Friction coefficient for the HS rotor $F_{h}$ & $7 \mathrm{e}-3 \mathrm{Nm} / \mathrm{rad} / \mathrm{s}$ \\
\hline Friction coefficient for the LS rotor $F_{l}$ & $1.7 \mathrm{Nm} / \mathrm{rad} / \mathrm{s}$ \\
\hline
\end{tabular}

First of all, we can observe in Fig. 5 to Fig . 7 that the direct starting on the grid is possible. The HS rotor reaches a speed of around $750 \mathrm{rpm}$ with a response time of less than 1s, whereas the LS rotor speed is around $50 \mathrm{rpm}$ in steady-state, which is in the gear ratio defined in (1). The maximum LS rotor torque reaches a value of $85 \mathrm{Nm}$ which doesn't exceed the pull-out torque of the magnetic gear $\left(\Gamma_{\max }=350 \mathrm{Nm}\right)$. We can observe significant oscillations during the transient phase. They are characterized by a pseudo-period of $140 \mathrm{~ms}$ and a very low damping coefficient. This is a classical behavior for magnetic gear that exhibits a low value for the torsional stiffness compared to a mechanical gear (Desvaux, 2016). These large oscillations only exist during the transient (starting, sudden load torque...) and cause vibrations that can be the source of mechanical fragility and noise. Moreover, it can be problematic to achieve high performance for speed or position control in servomechanism applications.

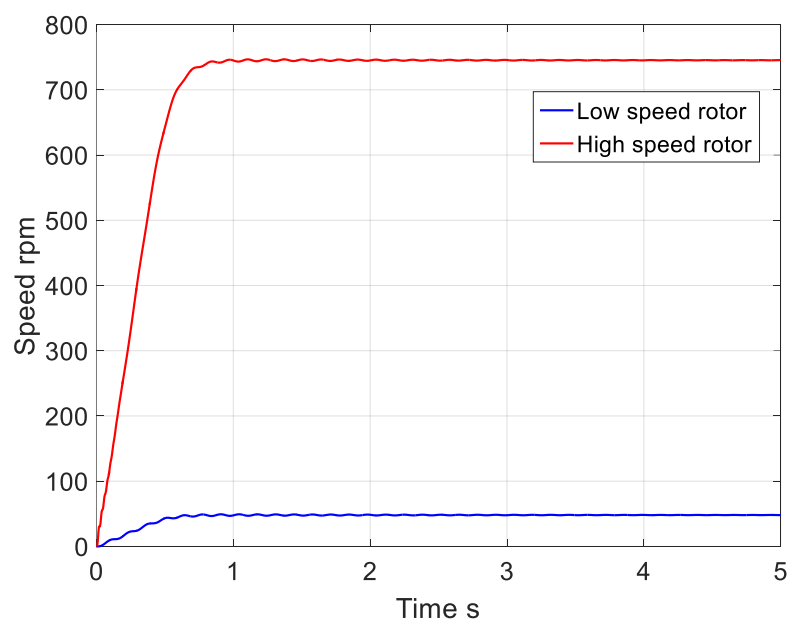

Fig. 5. Rotationnal speed for the LS and HS rotors during the start-up. 


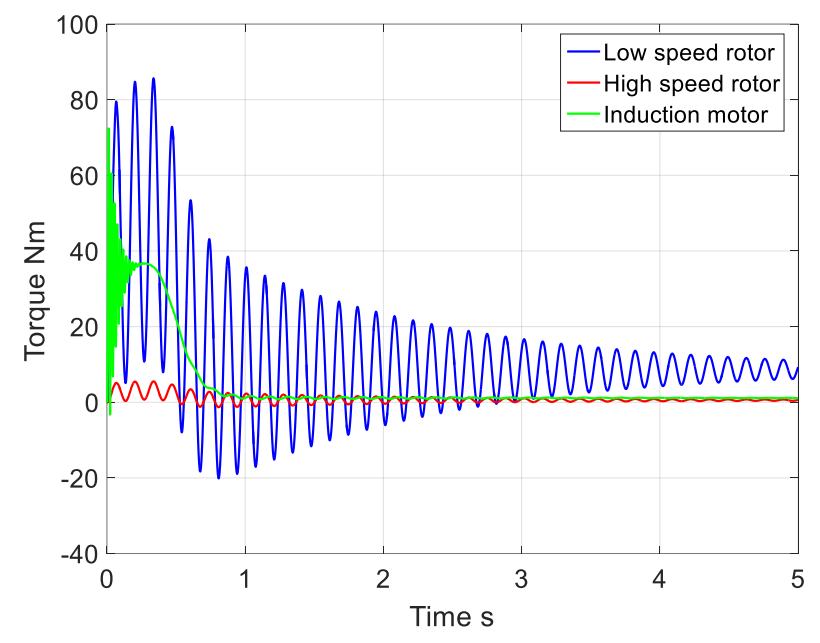

Fig. 6. Torque evolutions during the start-up.

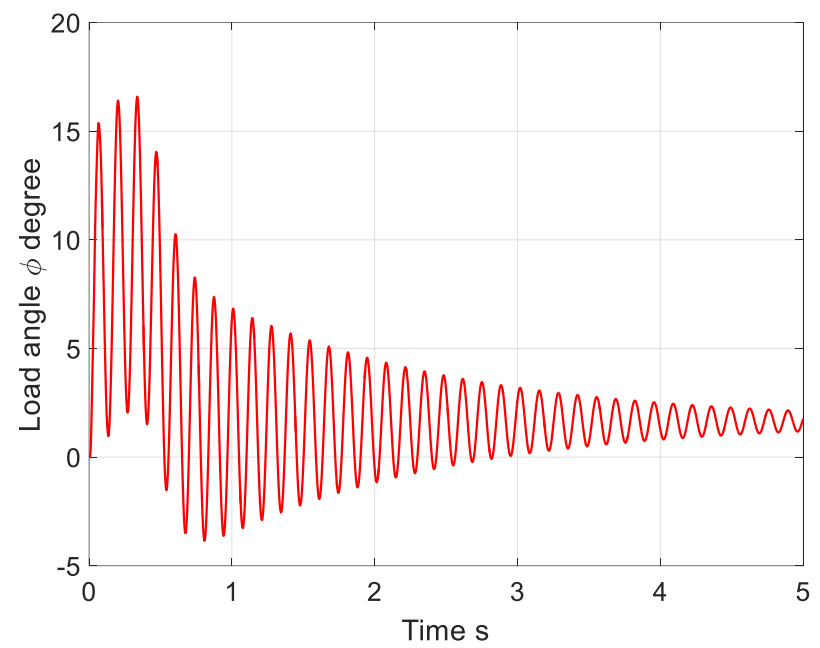

Fig. 7. Load angle variation during the start-up.

Fig. 7 shows that the load angle reaches a maximum value equal to $17^{\circ}$ during the starting, which remains much lower than $90^{\circ}$ corresponding to the stability limit for the magnetic gear.

\subsection{Response to a sudden load torque}

Once the machine has started, we applied a load torque step of $100 \mathrm{Nm}$ on the LS rotor at $t=5 \mathrm{~s}$. Fig. 8 to Fig. 10 show the transient responses for the low speed torque, the rotational speed of the HS and LS rotors, and for the load angle.

We can observe in Fig. 8 that this load torque step generates large oscillations on the LS torque $\Gamma_{l}$ with a maximum value of around $190 \mathrm{Nm}$. However, this maximum value remains lower than $\Gamma_{\max }$ and the operation remains stable after the transient. These oscillations are characterized by a pseudo-period of about $137 \mathrm{~ms}$, slightly lower than the $140 \mathrm{~ms}$ obtained under no-load condition. With the parameters listed in Tables 1 and 2 and from equations (10) and (11), we calculate a pseudo-period of 132 ms. Note that this value is close to the one obtained by the analytical approach based on the linearized model which uses Taylor's first order approximation.

As it can be seen in fig. 10, we can observe the same oscillation for the load angle during the transient. The value of the load angle $\Phi$ does not exceed $40^{\circ}$. Regarding the rotational speed of the LS and HS rotors shown in Fig. 9, we obviously note that their values decrease when the torque step is applied. Also, we can observe low speed ripples during the transient phase. This is due to the large value of the inertia. 


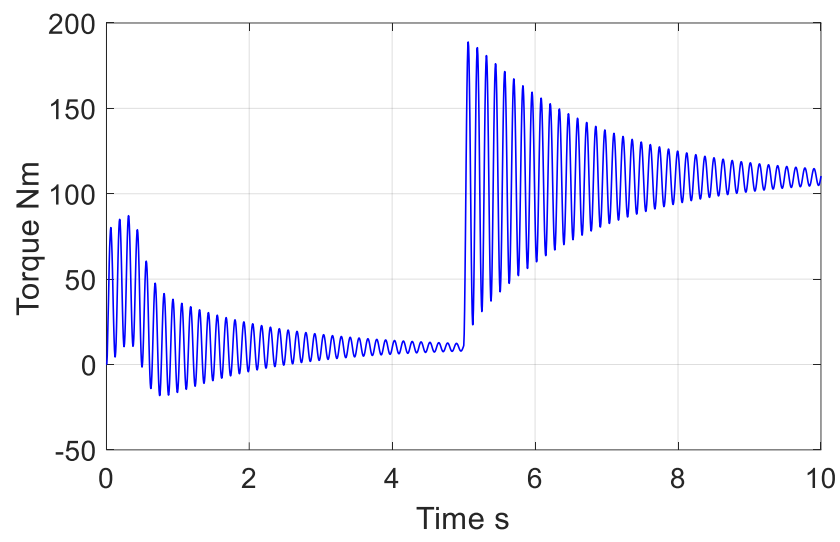

Fig.8. Low speed torque $\Gamma_{1}$ for a step load torque of $100 \mathrm{Nm}$ at $\mathrm{t}=5 \mathrm{~s}$.

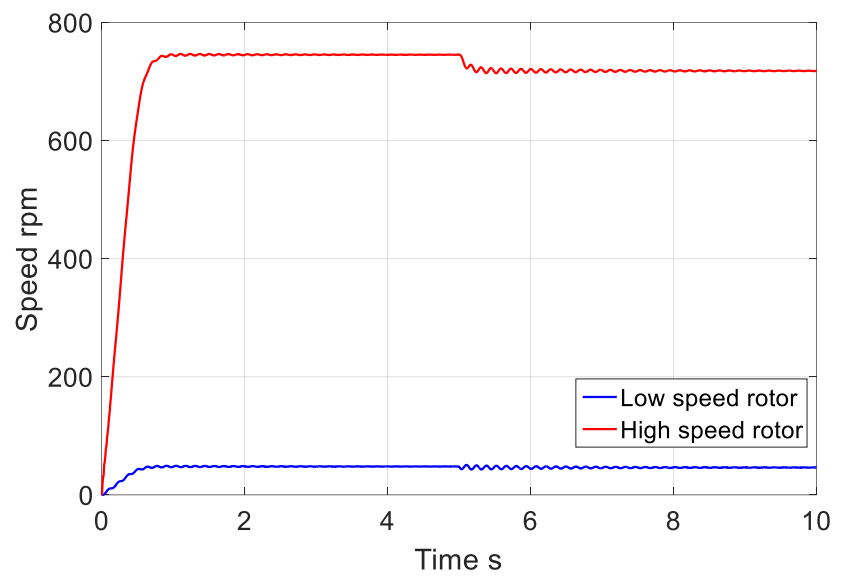

Fig.9. Rotational speed of the HS and the LS during during a step load torque of $100 \mathrm{Nm}$ at $\mathrm{t}=5 \mathrm{~s}$.

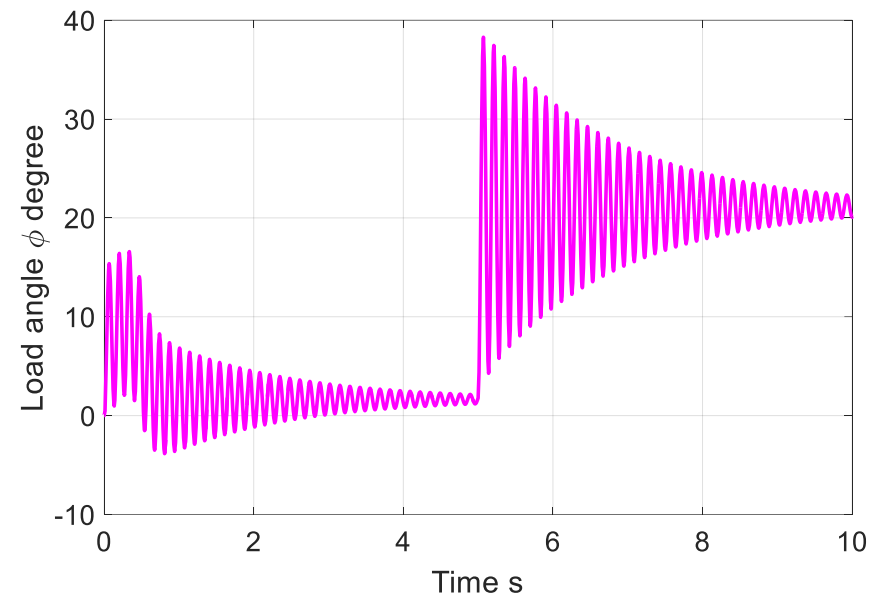

Fig.10. Load angle variation during during a step load torque of $100 \mathrm{Nm}$ at $\mathrm{t}=5 \mathrm{~s}$.

Fig. 11 and Fig. 12 show that the stability is maintained for a step load torque of $210 \mathrm{Nm}$ that corresponds to the rated torque of the MaGIM. We can observe in Fig. 12 that the load angle reaches a value of around $100^{\circ}$ during the transient without the loss of stability. It is important to make the difference between the dynamic stability and the static stability. As for a synchronous machine, it is well known that the load angle may exceed the value of $90^{\circ}$ during the transient, as shown in Fig. 12 , without the loss of stability at steady state. The stability can be predicted by the method of area equality but this is out of the scope of this paper. It greatly depends on the pull-out torque value of the magnetic gear $\left(\Gamma_{\max }=350 \mathrm{Nm}\right)$ compared to the nominal torque of the MaGIM. Here the magnetic gear has been designed to keep a margin of more than $100 \mathrm{Nm}$ in order to ensure the stability under transient and steady-state conditions. 


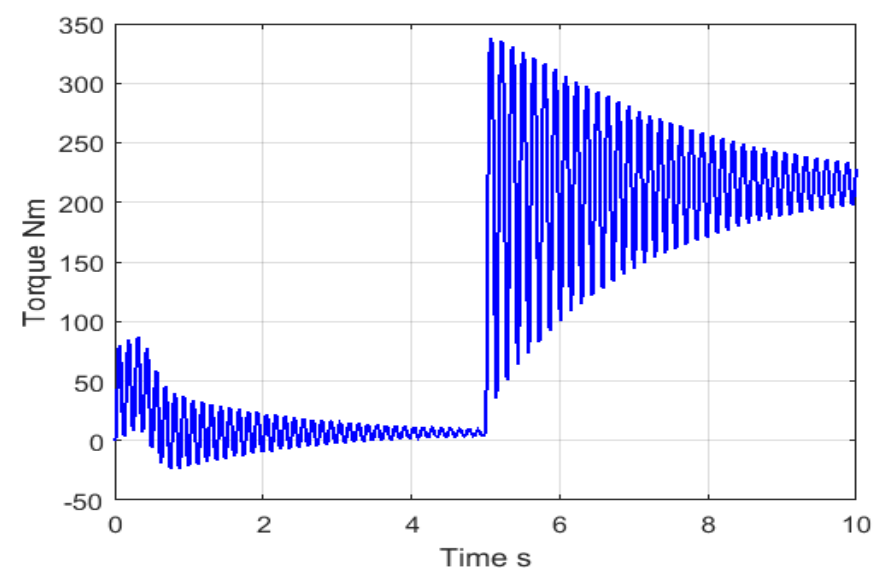

Fig.11. Low speed torque $\Gamma_{1}$ for a step load torque of $210 \mathrm{Nm}$ (rated torque) at $\mathrm{t}=5 \mathrm{~s}$.

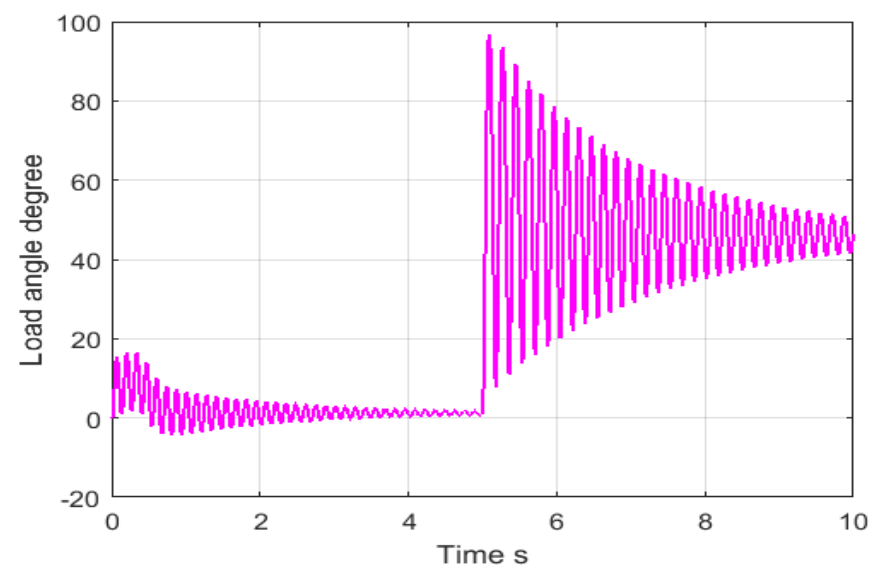

Fig.12. Load angle variation during a step load torque of $210 \mathrm{Nm}$ at $\mathrm{t}=5 \mathrm{~s}$

\subsection{Overload condition}

It is well known that magnetic gears offer substantial advantages compared to mechanical gears such as reduced maintenance, improved reliability, minimum acoustic noise and inherent overload protection (Atallah 2001, Rasmussen 2005, Hafla 2007, Lubin 2010). In this sub-subsection, we present some results related to the self-overload protection inherent to magnetic gears. To highlight this phenomenon, we apply $(t=5 \mathrm{~s})$ a load torque of $400 \mathrm{Nm}$ which is higher than $\Gamma_{\max }$. Figs. 13 to 15 show the speed variation of the HS and LS rotors, and the low speed torque, respectively.

As can be seen in Fig. 14, this operation causes the stall of the low speed rotor. That results in significant oscillations on the output torque (between -350 and $+350 \mathrm{Nm}$ ). As shown in Fig. 13, the HS rotor continues to rotate at a speed of $750 \mathrm{rpm}$ because the induction machine is connected to the grid. This operation is harmful for the MaGIM due to the vibratory movement of the low speed rotor which can cause mechanical wear. In an extreme case characterized by prolonged operation in this state, the deterioration of the device may be irreversible. It is therefore important to stop the power supply rapidly. 


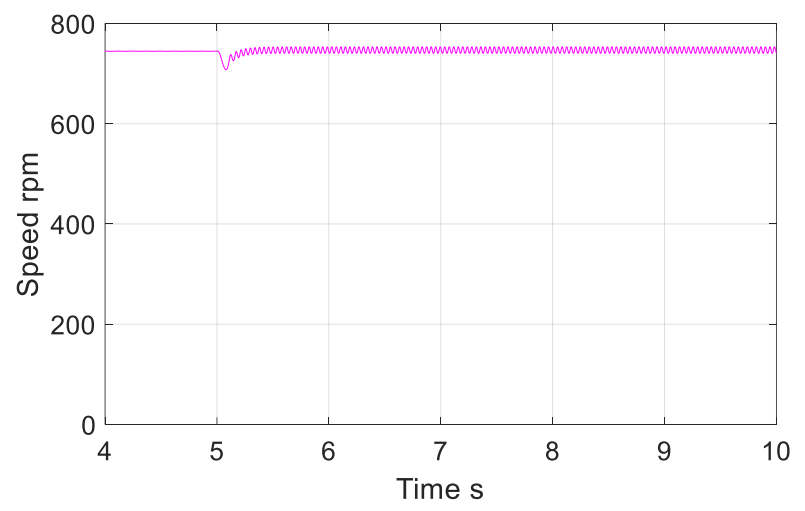

Fig. 13. HS rotor speed in overload condition.

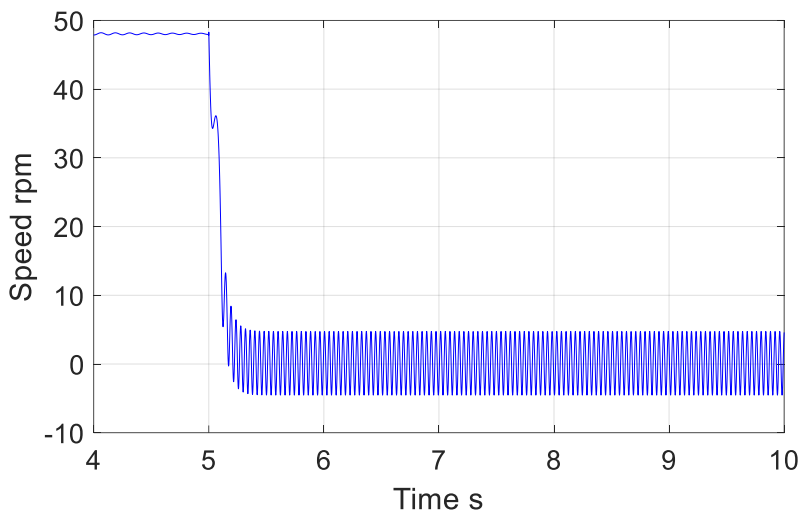

Fig. 14. LS rotor speed in overload condition.

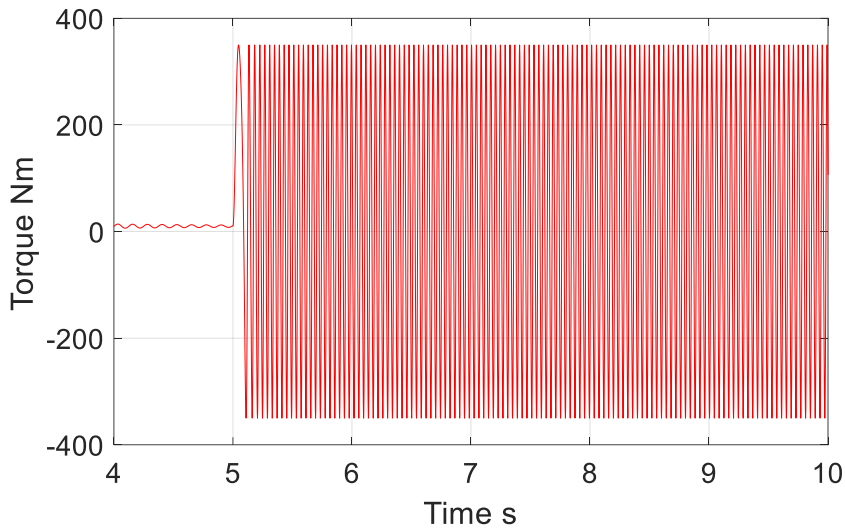

Fig. 15. Low speed torque in overload condition.

\subsection{Sinusoidal disturbance on the load torque}

In order to show the impact of the resonant frequency on the MaGIM behavior, we apply a load torque characterized by an average value $\Gamma_{0}=100 \mathrm{Nm}$ and a sinusoidal variation. This sinusoidal variation is defined by a small amplitude $\Delta \Gamma=10 \mathrm{Nm}$ and a frequency $\omega$ (12). Fig. 16 shows the load torque variations with $\omega=4 \mathrm{rd} / \mathrm{s}$.

$$
\Gamma_{c h}=\Gamma_{0}+\Delta \Gamma \cdot \sin (\omega t)
$$


In order to study the impact of the frequency $\omega$ on the performance of the MaGIM, simulations are done for three values of $\omega$ by using the non-linear model: $\omega<\omega_{0}, \omega=\omega_{0}$ and $\omega>\omega_{0}$ where $\omega_{0}$ is given by (10). For a mean load torque of $100 \mathrm{Nm}$ $\left(\Phi_{0}=18^{\circ}\right)$, the resonant frequency is equal to $\omega_{0}=47 \mathrm{rd} / \mathrm{s}$.

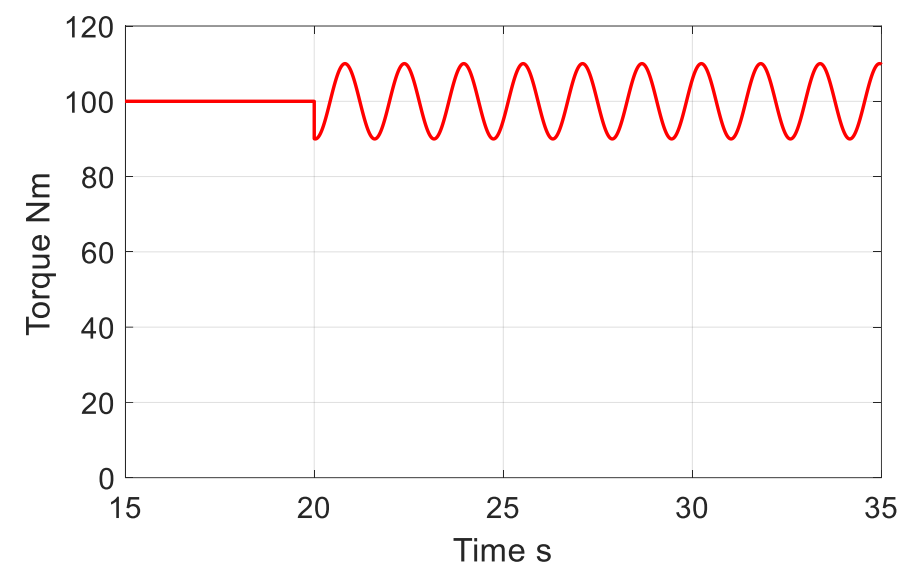

Fig. 16. Sinusoidal load torque variation with $\omega=4 \mathrm{rad} / \mathrm{s}$.

Fig. 17 to Fig. 19 show the load angle variation for $\omega=4 \mathrm{rd} / \mathrm{s}, \omega=\omega_{0}=47 \mathrm{rd} / \mathrm{s}$ and $\omega=100 \mathrm{rd} / \mathrm{s}$ respectively. When $\omega<\omega_{0}$, it can be seen in Fig .17 that the variation in the load angle remains small because of the frequency value being far from the resonant frequency. We observe the same behavior in Fig .18 which is obtained for $\omega>\omega_{0}$ but with a more prononciate attenuation for the load angle, as it can be predicted by the Bode diagram of Fig. 4.

If the frequency value is equal to the resonant frequency $\left(\omega=\omega_{0}\right)$, the system is severely disrupted, as shown in Fig. 19 where the variation on the load angle is very important and generates large oscillation on the rotor speed which can lead to mechanical problems.

It is worth noting that all these behaviors can be predicted by using the Bode diagram given in Fig. 4 and by the analytical expression of the resonant frequency given in (10).

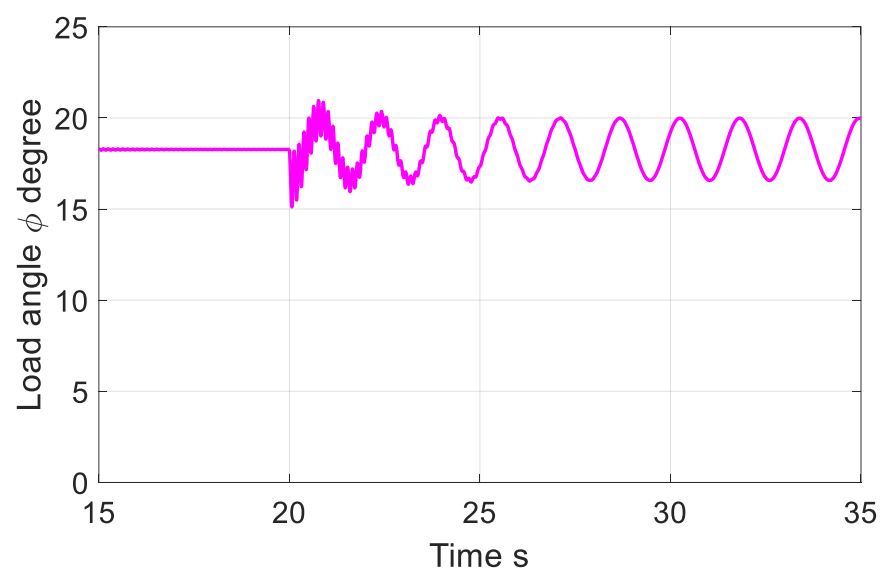

Fig. 17. Load angle variation for $\omega=4 \mathrm{rad} / \mathrm{s}$. 


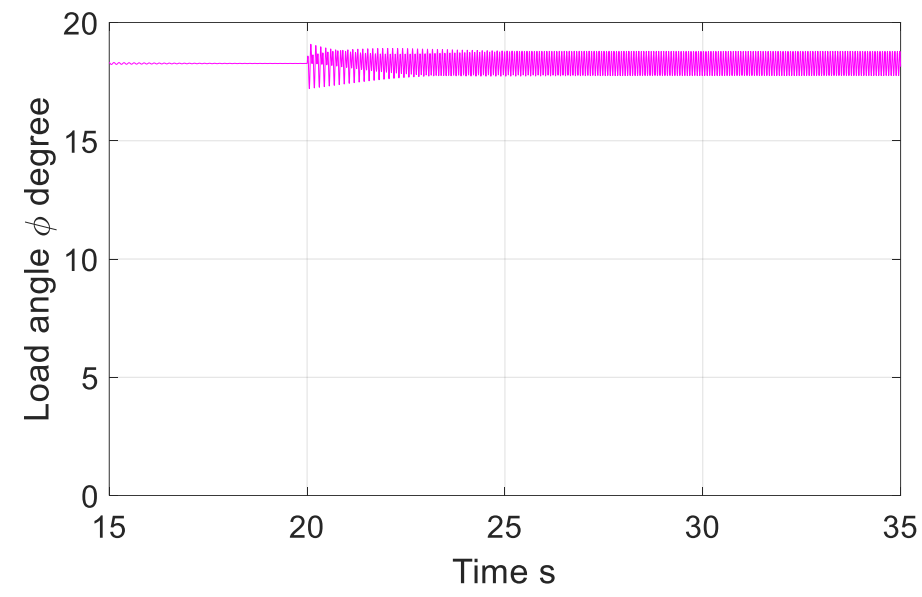

Fig. 18. Load angle variation for $\omega=100 \mathrm{rad} / \mathrm{s}$.

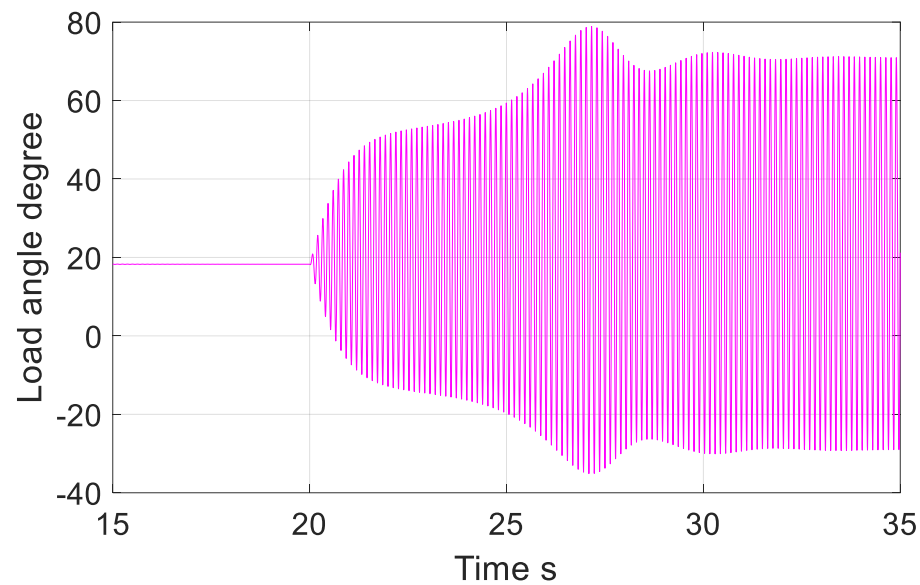

Fig. 19. Load angle for sinusoidal torque of $\omega=\omega_{0}=47 \mathrm{rad} / \mathrm{s}$.

\subsection{Impact of the low speed inertia $J_{l}$ on the transient response}

As mentioned previously, it is necessary to avoid any operation around the resonant frequency otherwise the risk of instability of the system increases that could lead to a stalling scenario. Since the expression of the resonant frequency $\omega_{0}(10)$ depends on the values of the parameters $K, J_{l}, G_{r}$ and $J_{h}$, and since only the inertia of the LS rotor can vary with the load $\left(K, G_{r}\right.$ and $J_{h}$ depend on fixed geometric parameters), we study in this part the impact of the LS inertia $J_{l}$ on the system behavior during the transient.

Fig. 20 shows the speed of the HS and LS rotors for a direct-on-line starting with a LS rotor inertia fixed to $J_{l}=50 \mathrm{~kg} \cdot \mathrm{m}^{2}$ (around 10 times the one corresponding to Fig. 5). We notice significant oscillations and a relatively long time response in comparison to Fig. 5 but starting is still possible. The load angle shown in Fig. 21, presents large oscillation during the transient phase with a maximum value of about $120^{\circ}$. This peak value is higher than $90^{\circ}$. However, there is no uncoupling between the HS and the LS rotors. This is due to the well-known dynamic stability criteria, which is equivalent to that of a synchronous machine connected to the grid (equal area criterion). This value for the LS rotor moment of inertia $J_{l}$ is designated as a critical value since, as shown in Fig. 22 and Fig. 23, beyond a value of $50 \mathrm{~kg} \cdot \mathrm{m}^{2}$ the machine stalls for $J_{l}=53 \mathrm{~kg} \cdot \mathrm{m}^{2}$. It is clear from Fig. 22 that the LS rotor does not start whiles the HS rotor is rotating, therefore the load angle tends toward infinity as show in Fig .23 . 


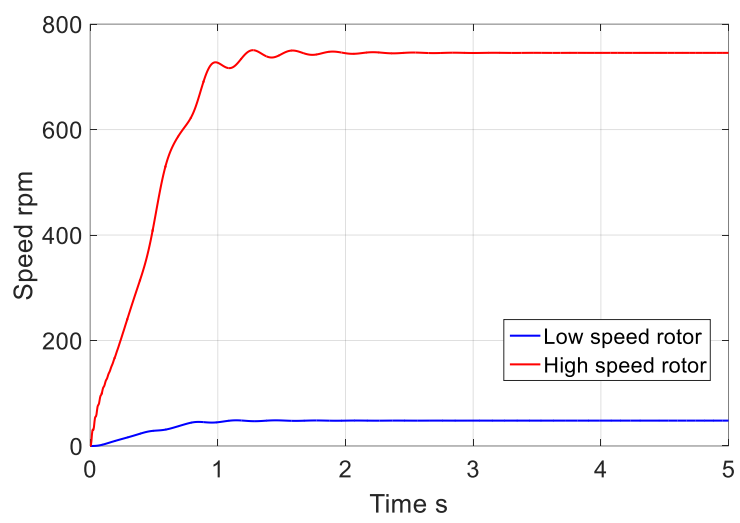

Fig.20. Rotational speed of the HS and the LS for $J_{l}=50 \mathrm{~kg} \cdot \mathrm{m}^{2}$.

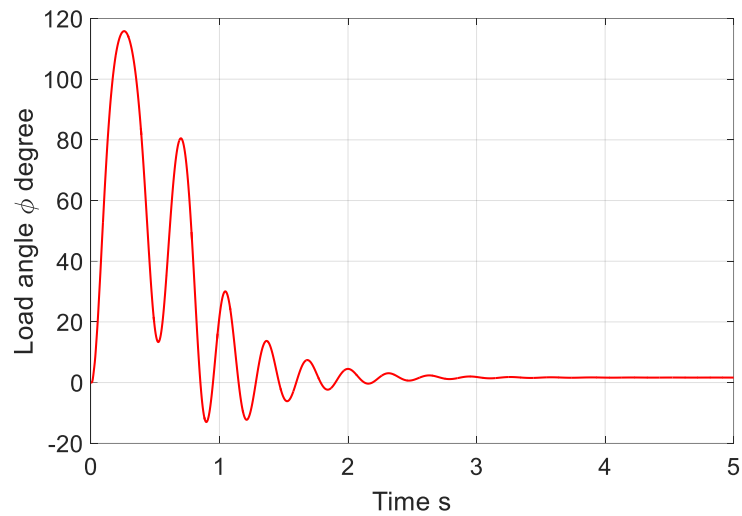

Fig.21. Load angle variation for $J_{l}=50 \mathrm{~kg} \cdot \mathrm{m}^{2}$.

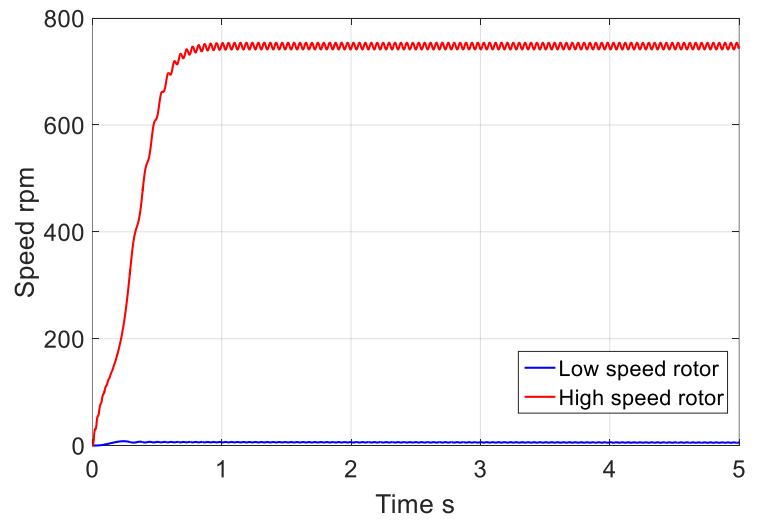

Fig.22. Rotational speed of the HS and the LS rotors for $J_{l}=53 \mathrm{~kg} . \mathrm{m}^{2}$.

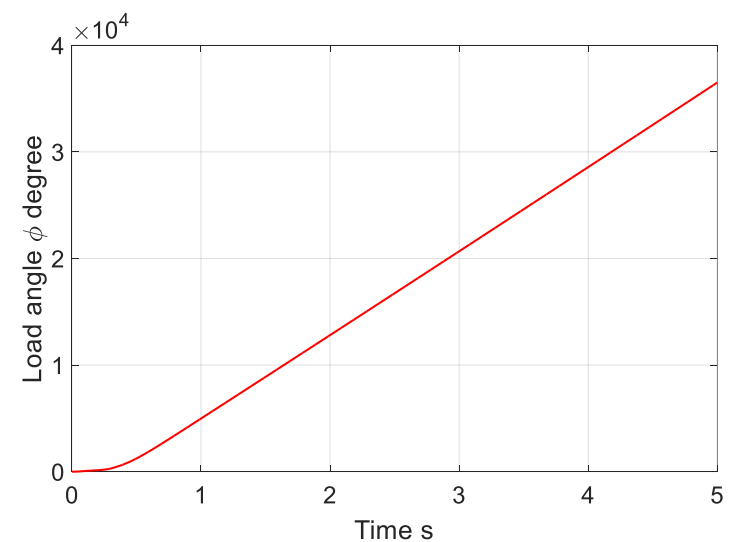

Fig.23. Load angle variation for $J_{l}=53 \mathrm{~kg} \cdot \mathrm{m}^{2}$. 


\section{Conclusion}

This paper presents the transient performances for a new type of electrical machine, the MaGIM. The MaGIM consists of an IM machine coupled to a magnetic gear. This new electrical machine can be used for applications directly connected to the grid that requires low speed and high torque. Dynamic simulations for a direct-on-line starting for no load and for a sudden variation of load torque were presented. The overload self-protection of the machine was shown as a result of a load torque higher than the maximum torque. We have given a simple expression for the resonant frequency of the MaGIM and we have shown its validity in different cases. Finally, we studied the impact of the mechanical parameters on the transient behavior, especially the one which involves the moment of inertia of the LS rotor. Its shown that there is a maximum limit that must not be exceeded otherwise the MaGIM will not start.

\section{REFERENCES}

Adkins B., and Harley R. G., (1975) "The General Theory of Alternating Current Machines," Chapman and Hall, London, 279pp.

Atallah K., and Howe D., (2001) "A Novel High-Performance Magnetic Gear," IEEE Trans. Magn, vol. 37, no. 4, pp. 28442846.

Bidouche B., Lubin T., and Mezani S., (2018) "Design and analysis of a magnetically geared induction machine" International Conference on Electrical Machines, ICEM 2018, Alexandroupoli, Greece.

Bouheraoua M., Wang J., Atallah K. (2015), "Slip recovery and prevention in pseudo direct drive permanent-magnet machines," IEEE Transactions on Industry Applications, vol. 51, no. 3, pp. 2291 - 2299.

Brown J. E., Kovacs K. P., and Vas P. (1983) "A method of including the effects of main flux path saturation in the generalized equations of a.c. machines,” IEEE Trans. Power App. and Syst., vol. PAS-102, no. 1, pp.96-103.

Da Costa Neves, C. and Flores Filho, A. (2016), "Analysis of a magnetic gear integrated Halbach generator", COMPEL - The international journal for computation and mathematics in electrical and electronic engineering, vol. 35, no. 6, pp. 1925-193

Desvaux M., Latimier R.,. Multon B., Sire S., and Ben Ahmed H., (2016) "Analysis of the dynamic behaviour of magnetic gear with nonlinear modelling for large wind turbine", International Conference on Electrical Machines, ICEM 2016, Lausane, Switzerland.

Filippini M., and Alotto P. (2017), “An optimization tool for coaxial magnetic gear”, COMPEL - The international journal for computation and mathematics in electrical and electronic engineering, vol. 36, no. 5, pp. 1526-1539.

Frank N. W., Pakdelian S., Toliyat H. A., (2011) "Passive Suppression of Transient Oscillations in the Concentric Planetary Magnetic Gear” IEEE Transactions on Energy Conversion, Vol. 26, no. 3, pp. 933-939. 
Hafla W., Buchau A., Rucker W.M, Weinläder A., and Klotz B. (2007), "Efficient design analysis of a novel magnetic gear on a high performance computer", COMPEL - The international journal for computation and mathematics in electrical and electronic engineering, vol. 26, no. 3, pp. 712-726.

Ho S. L., Niu S., and Fu W. N., (2010), "Transient analysis of a magnetic gear integrated brushless permanent magnet machine using circuit-field-motion coupled time-stepping finite element method," IEEE Trans. Magn., vol. 46, no. 6, pp. 2074-2077

Liu X., Chau K. T., Jiang J. Z., and Yu C., (2009) "Design and analysis of interior magnet outer-rotor concentric magnetic gears," J. Appl. Phys., vol. 105, no. 7, pp. 07F101-1-07F101-3.

Lubin T., Mezani S., and Rezzoug A. (2010), "Analytical computation of the magnetic field distribution in a magnetic gear," IEEE Trans. Magn., vol. 46, no. 7, pp. 2611-2621.

Mezani S., Hamiti T., Belguerras L., Lubin T., Rashed M., and Gerada C., (2015) "Magnetically Geared Induction Machines" IEEE Trans. Magn., vol. 51, no. 11, 8111404.

Montague R., Bingham C. (2013), "Nonlinear Control of Magnetically-geared Drive-trains" International Journal of Automation and Computing, vol. 10, no. 4, pp. 319-326.

Rasmussen P. O., Andersen T. O., Jorgensen F. T., and Nielsen O. (2005), "Development of a high-performance magnetic gear," IEEE Trans. Ind. Appl., vol. 41, no. 3, pp. 764-770.

Zhu Z. Q., and Howe D. (2000), "Influence of Design Parameters on Cogging Torque in Permanent Magnet Machines," IEEE Transaction on Energy conversion, vol. 15, no. 4, pp. 407-412. 